\title{
Clinical and economic burden of invasive fungal diseases in Europe: focus on pre-emptive and empirical treatment of Aspergillus and Candida species
}

\author{
L. Drgona • A. Khachatryan - J. Stephens • \\ C. Charbonneau • M. Kantecki • S. Haider • R. Barnes
}

Received: 30 April 2013 / Accepted: 29 July 2013 / Published online: 12 September 2013

(C) The Author(s) 2013. This article is published with open access at Springerlink.com

\begin{abstract}
Invasive fungal diseases (IFDs) have been widely studied in recent years, largely because of the increasing population at risk. Aspergillus and Candida species remain the most common causes of IFDs, but other fungi are emerging. The early and accurate diagnosis of IFD is critical to outcome and the optimisation of treatment. Rapid diagnostic methods and new antifungal therapies have advanced disease management in recent years. Strategies for the prevention and treatment of IFDs include prophylaxis, and empirical and pre-emptive therapy. Here, we review the available primary literature on the clinical and economic burden of IFDs in Europe from 2000 to early 2011, with a focus on the value and outcomes of different approaches.
\end{abstract}

Electronic supplementary material The online version of this article (doi:10.1007/s10096-013-1944-3) contains supplementary material, which is available to authorized users.

\section{Drgona \\ Department of Haematology/Oncology, National Cancer Institute and Comenius University, Bratislava, Slovakia}

\author{
A. Khachatryan $\cdot$ J. Stephens $(\bowtie)$ \\ Pharmerit International, 4350 East West Highway, Suite 430, \\ Bethesda, MD 20814, USA \\ e-mail: jstephens@pharmerit.com \\ C. Charbonneau \\ Pfizer Global Outcomes Research, Pfizer Inc., New York, NY, USA
}

M. Kantecki

Pfizer International Operations, Pfizer Inc., Paris, France

S. Haider

Pfizer Global Research and Development, Pfizer Inc., Groton, CT, USA

\section{R. Barnes}

Cardiff University School of Medicine, Cardiff, UK

\section{Introduction}

Opportunistic invasive fungal diseases (IFDs) are a significant cause of morbidity and mortality in immunocompromised patients, and are associated with increased healthcare costs [1].

Early diagnostics can improve treatment outcomes and potentially reduce IFD-associated costs. Microscopy and histology are practical and inexpensive methods for IFD detection, but cannot identify organisms to the species level and are often invasive. Non-invasive methods include techniques to detect fungal antigens (e.g. galactomannan, mannan, $\beta$-D-glucan) or fungus-specific nucleic acids [polymerase chain reaction (PCR)], or rely on specific radiological and clinical signs. IFDs can be classified as possible, probable or proven based on host, clinical and microbiological features using the European Organization for Research and Treatment of Cancer/Mycoses Study Group (EORTC/MSG) criteria [2].

In addition to the antifungal treatment of confirmed diseases, approaches include prophylaxis, empirical therapy and pre-emptive/diagnostic-driven therapy. Prophylaxis is recommended for the prevention of infection in high-risk patients [3-6]. Empirical therapy is an early approach in patients with persistently febrile neutropaenia unresponsive to antibiotic therapy. Pre-emptive/diagnostic-driven therapy is usually based on the presence of specific clinical signs and fungal biomarkers, but there is no consensus on the definition and there may be overlap with empirical and targeted therapy (Fig. 1) [7, 8].

Polyenes, azoles and echinocandins are used to treat IFDs. These agents demonstrate high levels of antifungal activity, although resistance is reported for all classes. Antifungal treatment can be hampered by toxicity, poor tolerability or a narrow activity spectrum, and limitations have driven efforts to determine the efficacy of combination therapy, but no 
Fig. 1 Variable definitions of treatment strategies and relative positions within the treatment continuum

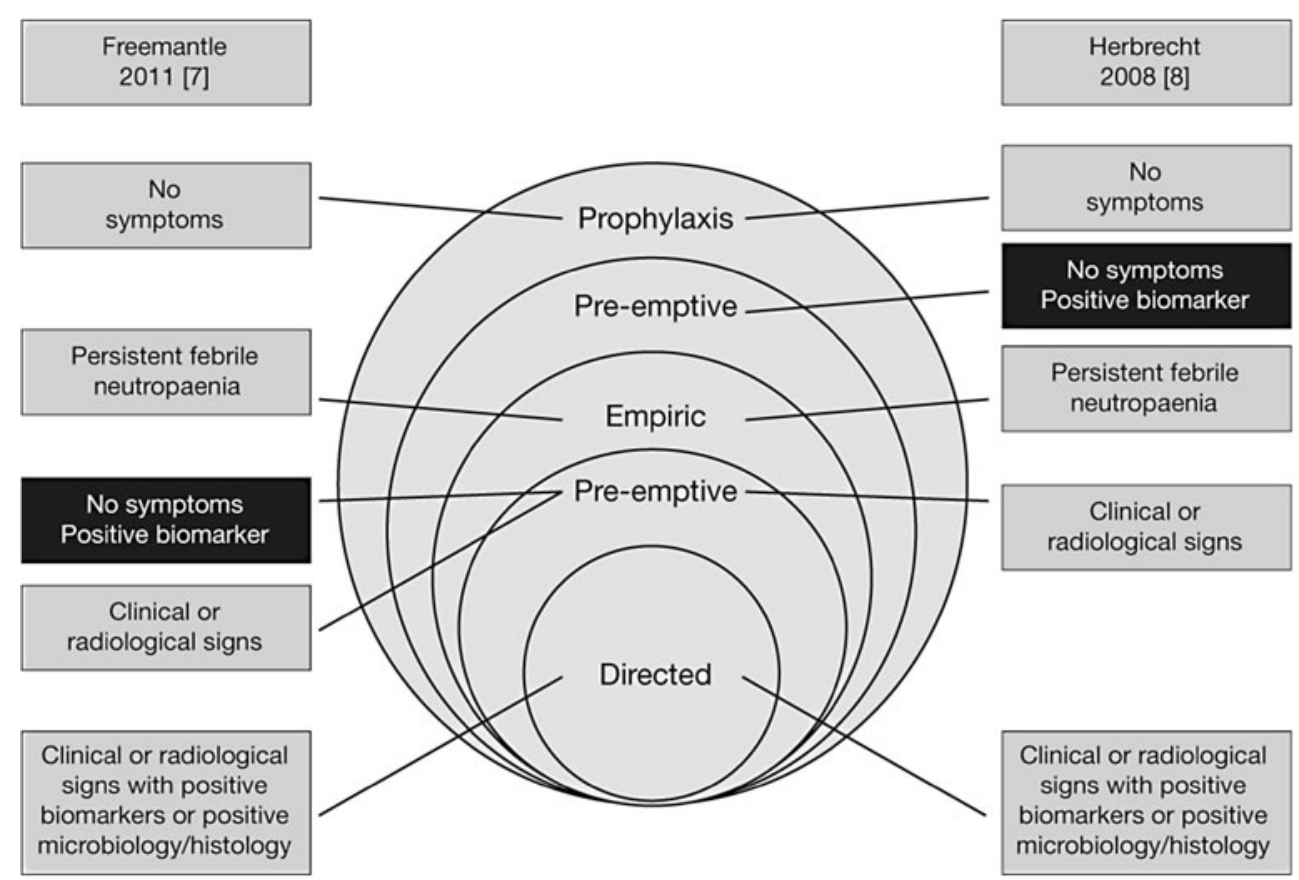

optimal treatment strategy has been identified [9]. The Infectious Diseases Society of America (IDSA) currently recommends fluconazole or an echinocandin as the firstline therapy for candidiasis in non-neutropaenic patients; for neutropaenic patients, initial therapy with echinocandins is preferred until the Candida species is identified [10]. Voriconazole is the recommended therapy for invasive aspergillosis (IA) [11-13].

The aim of this article is to review the primary evidence on the clinical and economic burden of IFDs in Europe, encompassing the value and treatment outcomes of different diagnostic and therapeutic approaches to management.

\section{Methods}

A strategic literature review was conducted to understand the clinical burden of IFD in terms of epidemiology, outcomes and treatment trends, and the economic burden of IFD contributing to overall healthcare resource utilisation (HCRU), including hospitalisations, length of stay (LOS) in hospital, diagnostic procedures and additional treatment and medications.

\section{Literature search}

PubMed/MEDLINE and EMBASE were searched to identify the primary literature on IFDs (Supplementary Table 1). Searches were limited to results published in English; during the last 10 years (2000 to early 2011); and having reported on human subjects. Abstracts from clinical congresses [International Society for Pharmacoeconomics and Outcomes Research (ISPOR), Interscience Conference on Antimicrobial Agents and Chemotherapy (ICAAC), IDSA and the European Society of Clinical Microbiology and Infectious Diseases (ECCMID)] were searched for data that may still have been in press. Abstract searches were limited to results published in English; during the last 5 years (2005 to 2010); and having reported on human subjects. Key review papers and reports issued by disease surveillance agencies were utilised to define targeted searches.

\section{Study eligibility and selection criteria}

Available abstracts, full-text articles and other materials were reviewed for inclusion using the criteria in Supplementary Table 2.

\section{Results}

Literature analysis

In total, 224 primary literature articles and 194 clinical abstracts were identified. After eligibility criteria were applied, 113 primary literature articles and 55 clinical abstracts were reviewed. Bibliographies were screened, which identified 12 primary literature articles. The final literature field consisted of 57 primary literature articles and 18 clinical abstracts (Fig. 2) [14-88]. Two additional posters from Slovakia 


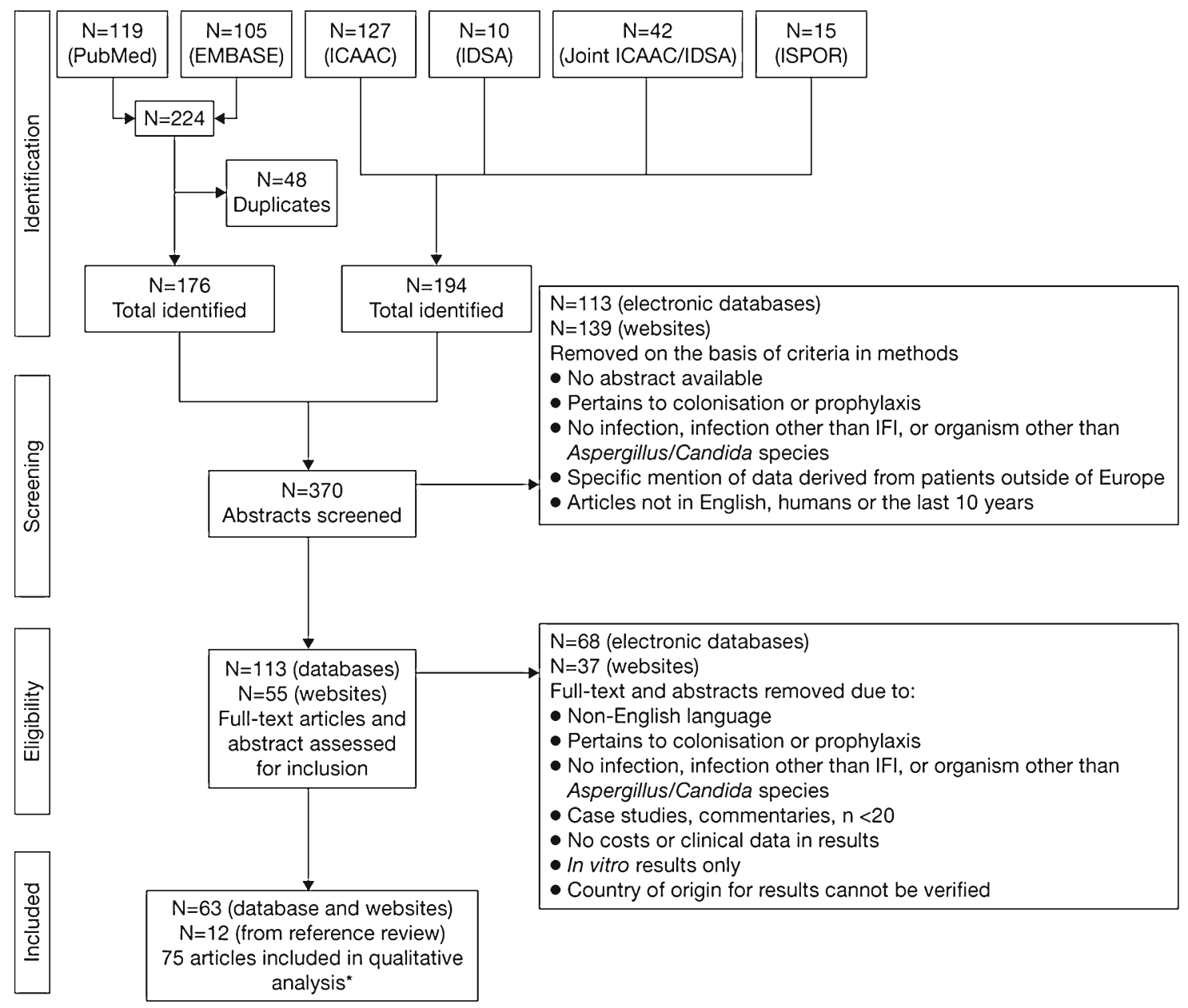

\begin{abstract}
"After the literature search was completed, two additional posters from Slovakia were provided by the sponsor and were included in the analysis
ICAAC: Interscience Conference on Antimicrobial Agents and Chemotherapy, IDSA: Infectious Diseases Society of America, IFI: invasive fungal infection, ISPOR: International Society for Pharmacoeconomics and Outcomes Research
\end{abstract}

Fig. 2 Flow diagram for literature identification

were later provided by the sponsor and included in the analysis $[89,90]$.

\section{Clinical burden: mortality}

\section{IFD-related mortality}

Twenty-one studies were identified across ten countries, including one European-wide study, which explicitly reported IFD-related or attributable mortality. However, a clear definition of IFD-related death was lacking in many studies, with criteria ranging from all deaths during the study to patients with hyphal invasion on autopsy. Many patients had underlying conditions; differentiating mortality related to these conditions from deaths directly caused by IFD was problematic. Furthermore, the proportion of IFD-attributable deaths was calculated using a variety of methods (e.g. in relation to the total number of deaths or in relation to the total population). Supplementary Table 3 reports the rates of IFD-related mortality and risk factors by European country.

\section{Overall mortality}

The overall 28- or 30-day mortality burden in patients with IFDs ranged from 1.5 to $82.4 \%$, with most estimates falling between 35 and $45 \%$. Three studies fell outside this range, with mortality estimates of $<30$ and $>45 \%[20,33,39]$. These mortality rates may be explained by specific patient populations, with the highest 28 -day mortality rates $(66.7-82.4 \%)$ in patients in an intensive care unit (ICU) with probable or proven IA [20].

The 12 -week overall mortality ranged from 22 to $47 \%$ [15, $19,33,51,61]$. Other time frames for mortality measures were 7, 14, 42, 60 and 100 days, 4 months and 4 years, and 
mortality estimates ranged from $5 \%$ in haematopoietic stem cell transplant (HSCT) patients (at 100 days) [82] to $70.6 \%$ (at 14 days) in an ICU population with IA [20]. Twenty-one studies reported mortality over an unspecified time frame. The highest overall mortality rate $(90 \%)$ was reported in paediatric patients with haematological malignancies and IA [76], and in ICU patients with Candida non-albicans infection [45].

The overall mortality due to Candida infection ranged from 20 to $90 \%$; however, after the exclusion of ICU populations, this narrowed to $20-32 \%$. In a study by Almirante and colleagues, the rates of overall mortality of 23 and $43 \%$ were reported for patients with $C$. parapsilosis and $C$. albicans, respectively $(p=0.003)$ [64].

The overall mortality range for Aspergillus infections was $30-90 \%$, and remained high, irrespective of whether known ICU populations were excluded.

These results indicate that mortality rates in patients receiving antifungal treatment depend on the time period over which mortality is measured, the responsible organism and the underlying disease characteristics of the patient.

\section{Diagnosis of IFD}

\section{Antigen-based assays}

Galactomannan testing for the diagnosis of Aspergillus infections was reported in 20 studies across ten countries. All of the studies used serum specimens, and three also used bronchoalveolar lavage (BAL) fluid [15, 22, 61]. BAL testing was preferred in the study by Slobbe and colleagues [61], and serum was only used when a bronchoscopy could not be performed. The testing frequency ranged from twice weekly $[28,78,79]$ to daily monitoring [17] as part of a screening strategy. Four studies measured galactomannan following a triggering event as part of an intensive diagnostic workup (IDWU) [18, 51, 57, 61]. Optical density cut-offs ranged from $>0.5$ to $\geq 1.5$; the most frequently used criteria for positivity was an optical density index $\geq 0.5$ for two consecutive tests.

Reports varied regarding the utility of galactomannan testing in the diagnosis of IFD. Barnes and colleagues investigated the use of a febrile neutropaenia care pathway that used routine biomarker testing in patients with acute leukaemia, refractory disease undergoing aggressive chemotherapy or undergoing HSCT [79]. In this study, 61 patients were positive for Aspergillus by PCR; of these, 25 (41\%) were positive using the galactomannan assay. Thirty-two patients were positive by galactomannan testing and all but seven were also positive by PCR. Thirty-six patients were positive by Aspergillus PCR alone. Antigen testing (galactomannan and mannan) was less sensitive than PCR but demonstrated good specificity. Combined antigen and PCR testing gave a sensitivity of 100 and $87.5 \%$ for single and multiple results, respectively, and a specificity of $100 \%$.

Girmenia and colleagues used galactomannan testing as part of an IDWU and reported detection in $89 \%$ of cases [51]. Galactomannan assays contributed to diagnosis in 26 of 100 IDWU as a result of at least two positive samples, while 42 of 100 IDWU computed tomography (CT) findings led to IFD diagnosis. Both galactomannan tests and high-resolution CT (HRCT) scans were positive in the same IDWU in $74 \%$ of patients who were diagnosed with pulmonary IFD. The detection of galactomannan occurred after a mean of 4.7 days (range 3-7 days) following the CT results in four cases, and galactomannan test results were negative despite positive culture findings in three cases [51]. No further data regarding the specificity or sensitivity were provided.

Mannan testing for the diagnosis of Candida infections was reported in two studies, each using a minimum cut-off of $0.5 \mathrm{ng} / \mathrm{ml}[56,79]$. In the aforementioned study by Barnes and colleagues [79], testing was performed twice weekly in conjunction with other biomarker tests. Eleven patients had positive Candida PCR results, five of whom also had a positive mannan antigen assay.

Posteraro and colleagues reported success with the use of Candida mannan screening versus Candida culture surveillance in BAL in the neonatal ICU [56]. Sixteen infants with positive mannan assays were compared with 16 historical controls with positive surveillance cultures. The incidence of IFD in the surveillance culture group was $23 \%$; no cases of IFD were reported in the group undergoing mannan screening.

$\beta$-D-glucan is not specific for Aspergillus species and was only referred to in a nationwide Aspergillus registry in Austria, in which $(1,3) \beta$-D-glucan testing was used in $3 \%$ of cases as a diagnostic tool [15].

\section{PCR-based testing}

Studies conducted in the UK and Austria reported that PCR testing was routinely performed in 4 and $16 \%$ of cases, respectively $[15,41]$. PCR assays were used in a variety of ways in addition to screening/pre-emptive strategies. For example, in a study conducted in Germany, a positive PCR assay of BAL specimens was used in conjunction with suspicious CT findings for infection diagnosis [38]. By contrast, Rubio and colleagues performed PCR testing as a confirmation assay in patients who were positive for invasive filamentous fungal infection by pathology [76].

A prospective study conducted in Germany compared outcomes in patients following allogeneic HSCT who were treated empirically with antifungals versus those treated preemptively after PCR testing [39]. Patients treated with antifungals after a positive PCR assay had significantly decreased mortality at 30 days $(p=0.015)$, but this survival benefit did 
not persist at 100 days. Therefore, while pre-emptive treatment following a positive PCR assay appears to confer survival benefits, routine use in the clinical setting may present challenges [39].

Barnes and colleagues reported on the reproducibility and rapidity of PCR test results versus antigen testing by performing assays for both Aspergillus and Candida. All cases of proven disease were positive by both PCR and antigen testing [79]. A comparison of the PCR and galactomannan results revealed simultaneous positive results in six patients, a positive PCR prior to galactomannan testing in 15 patients and a positive galactomannan test prior to PCR in four patients [79].

\section{$H R C T$}

Most studies that reported use of HRCT were conducted in oncology patients; few details were provided regarding reasons for performing an HRCT scan (e.g. clinical suspicion or as part of routine monitoring). Weisser and colleagues reported on the use of HRCT scans in 161 episodes of infection in 107 patients with haematological malignancies [78]. Scans were performed once weekly or when clinically indicated. The halo sign, air crescent sign or cavitatory lesions were classified as major signs from HRCT scans, whereas all other infiltrates were classified as minor signs. Minor signs were reported in $43 \%$ of cases and major signs in $7 \%$ of cases; no infiltrate was seen with $50 \%$ of the infection episodes.

Two studies reported the use of diagnostic HRCT scans in populations other than oncology patients. In one study, a suggestive HRCT was noted in $41 \%$ of patients in a general hospital who had a positive pulmonary isolate for Aspergillus [63]. In the second study, which focused on critically ill patients with neutropaenia, an HRCT scan was performed in 17/67 patients with probable or proven IA with abnormalities on chest $\mathrm{X}$-ray. Of these, three patients had a halo sign and nine had cavitation. The remaining five patients had non-specific changes [17].

Early management approaches

\section{Prophylaxis}

The use of antifungal prophylaxis ranged from 28 to $100 \%$ in 21 identified studies across 12 countries. All azole- and amphotericin-type products were used, and fluconazole was the most frequently reported prophylactic agent. Most studies did not address breakthrough infections, although a rate of $30 \%$ was reported in an Austrian registry that defined breakthrough infection as proven fungal infection after 7 days of prophylaxis [15]. Therapeutic drug monitoring was not performed in this study; therefore, low drug concentrations could not be excluded as the reason for breakthrough infection.

\section{Empirical therapy}

Lafaurie and colleagues conducted a prospective chart review of empirical therapy in a heterogeneous population of patients admitted to haematology, oncology, ICU or infectious-disease wards in a French hospital [31]. Empirical treatment was initiated for refractory fever (39\%), recurrent fever (48 \%), clinical signs of sepsis $(5 \%)$ and tachycardia with elevated C-reactive protein (CRP) (4\%) [31]. Caspofungin was the first-line treatment in $71 \%$ of episodes, followed by liposomal amphotericin B (18\%) and amphotericin B deoxycholate (11\%) [31]. Eleven percent of patients had breakthrough infection (any IFD identified after 3 days of empirical treatment), although this could be attributed to the high-risk population.

In a second study focusing on empirical therapy, a retrospective chart review of patients undergoing induction of salvage chemotherapy for leukaemia given antifungal therapy on day 4 of fever with negative cultures was conducted [57]. The fungal-attributable mortality was $2.5 \%$, leading the authors to conclude that, while empirical therapy has become a controversial treatment modality, it may be of value in selected high-risk populations [57].

\section{Pre-emptive therapy}

Eight identified studies reported some form of a pre-emptive strategy, although definitions were diverse. Criteria for treatment initiation and the specific approaches used were different for all pre-emptive studies (Table 1). The presence of clinical signs and symptoms were triggers for treatment initiation in two studies $[28,79]$; HRCT scans alone or with clinical microbiological or positive galactomannan tests triggered treatment in five studies [17, 51, 74, 79, 82]; galactomannan testing was used in four studies [17, 25, 51, 79], with one study using the Candida mannan assay [79]; PCR testing was used in two studies [39, 79]. A variety of treatment regimens were given to patients. Seven studies pre-defined drug treatment, while one study did not [51].

Overall, pre-emptive treatment was initiated in 7.7-51.7\% of patients [17, 25, 39, 51, 74, 79, 82]. Most studies reported pre-emptive antifungal use of between 39.2 and $51.7 \%$. Three studies reported low rates of pre-emptive treatment initiation $[17,51,82]$. Maertens and colleagues had the lowest number of patients receiving therapy due to strict requirements for treatment initiation (two positive galactomannan assays or positive microbiological results with suggestive CT findings) [17]. Dignan and colleagues had strict definitions for antifungal treatment initiation, which resulted in $17 \%$ of patients receiving pre-emptive treatment [82]. Caspofungin was started: if there was a positive $\mathrm{CT}$ and neutropaenic fever; if a CT could not be performed within $24 \mathrm{~h}$; or at the discretion of the physician in patients who developed respiratory failure 
Table 1 Diagnostic methods in pre-emptive treatment

\begin{tabular}{|c|c|c|c|c|c|c|}
\hline \multirow[b]{2}{*}{ Reference } & \multirow[b]{2}{*}{ Country } & \multicolumn{5}{|c|}{ Pre-emptive group criteria } \\
\hline & & Clinical & HRCT & $\mathrm{GM} / \mathrm{M}$ & Microbiological & PCR \\
\hline \multicolumn{7}{|l|}{ Non-comparative studies } \\
\hline Maertens et al., 2005 [17] & Belgium & & $\mathrm{X}$ & $\mathrm{X}$ & $\mathrm{X}$ & \\
\hline Girmenia et al., 2010 [51] & Italy & & $\mathrm{X}$ & $\mathrm{X}$ & $\mathrm{X}$ & \\
\hline Posteraro et al., 2010 [56] & Italy & & & $\mathrm{X}$ & & \\
\hline Aguilar-Guisado et al., 2010 [74] & Spain & $\mathrm{X}$ & $\mathrm{X}$ & & $\mathrm{X}$ & \\
\hline Barnes et al., 2009 [79] & UK & $\mathrm{X}$ & $\mathrm{X}$ & $\mathrm{X}$ & $\mathrm{X}$ & $\mathrm{X}$ \\
\hline Dignan et al., 2009 [82] & UK & & $\mathrm{X}$ & & & \\
\hline \multicolumn{7}{|l|}{ Randomised, comparative studies } \\
\hline Cordonnier et al., 2009 [25] & France & $\mathrm{X}$ & $\mathrm{X}$ & $\mathrm{X}$ & & \\
\hline Hebart et al., 2009 [39] & Germany & & & & & $\mathrm{X}$ \\
\hline
\end{tabular}

GM galactomannan, $H R C T$ high-resolution computed tomography, $M$ mannan, $P C R$ polymerase chain reaction, $U K$ United Kingdom

with high dependency or were in the ICU [82]. In another study, only one patient in the pre-emptive therapy arm received treatment secondary to a negative IDWU and worsening clinical condition [51].

These findings indicate a lack of consensus and understanding of the definition of pre-emptive therapy. Therefore, the applicability of currently available data to the wider clinical setting is unclear.

\section{Empirical versus pre-emptive strategies}

Ten studies across six countries reported on some form of empirical or pre-emptive therapy. A summary of nonrandomised, observational studies of empirical and preemptive treatments in adult patients is presented in Table 2. Two prospective randomised studies conducted in oncology patients directly compared empirical and pre-emptive strategies (Table 3) [25, 39].

In the comparative studies, the incidence of IFDs ranged between 2.7 and $8.2 \%$ in empirically treated patients and between 8.2 and $9.1 \%$ in the pre-emptively treated patients $[25,39]$. In the study conducted by Cordonnier and colleagues, the difference in the IFD rate between the treatment groups was statistically significant (pre-emptive $9.1 \%$ vs. empirical $2.7 \%$, $p<0.02$ ) [25]. The rate of IFDs was significantly higher in a subgroup of patients who received induction therapy (16.4\%) versus patients who received consolidation therapy/autologous stem cell transplantation $(3.9 \%, p<0.01)$, with $15 / 17$ IFD cases occurring in the induction group and most infections occurring in the pre-emptive arm (12 cases of IFD). Despite the randomised study design, there were differences between the two treatment groups, which must be taken into account when interpreting these data. For example, greater morbidity was recorded for patients in the pre-emptive group versus the empirical group. Outcomes were similar between pre-emptive and empirical strategies in the study by Hebart and colleagues, where patient demographics were more consistent, all patients were on prophylaxis at baseline and only liposomal amphotericin B was used [39].

The overall mortality in the two comparative trials ranged from 1.5 to $16.5 \%$ and IFD mortality ranged from 0 to $13.2 \%$ $[25,39]$. The study by Cordonnier and colleagues demonstrated non-inferiority in the overall population between the empirical and pre-emptive groups with regards to survival at 2 weeks after recovery from neutropaenia [25]. In a subgroup analysis of patients who received induction therapy, the inferiority of pre-emptive versus empirical treatment in terms of 2-week survival could not be ruled out, but the study was not powered to prove this. This may be related to a longer median duration of neutropaenia in the pre-emptive versus the empirical arm in patients receiving induction therapy (26 days vs. 12 days, respectively). By contrast, non-inferiority was demonstrated for empirical versus pre-emptive treatment in a subgroup of patients who received consolidation therapy/ autologous stem cell transplantation. While empirical treatment may be comparatively beneficial versus pre-emptive treatment in patients receiving induction therapy (but not in patients receiving consolidation therapy), the differences between the groups in this study must be considered.

In the Hebart study, mortality at Day 100 did not differ between the pre-emptive and empirical groups, although the pre-emptive group had better survival at Day 30 [39]. Preemptive treatment was initiated after a positive PCR test; after Day 30, regular PCR testing became more difficult, as most patients had been discharged from hospital. A study with consistent PCR testing beyond 30 days would be instructive in delineating whether pre-emptive treatment confers a tangible survival benefit over empirical therapy.

The studies reviewed herein indicated that IFD cases may be missed less frequently when patients are treated pre- 


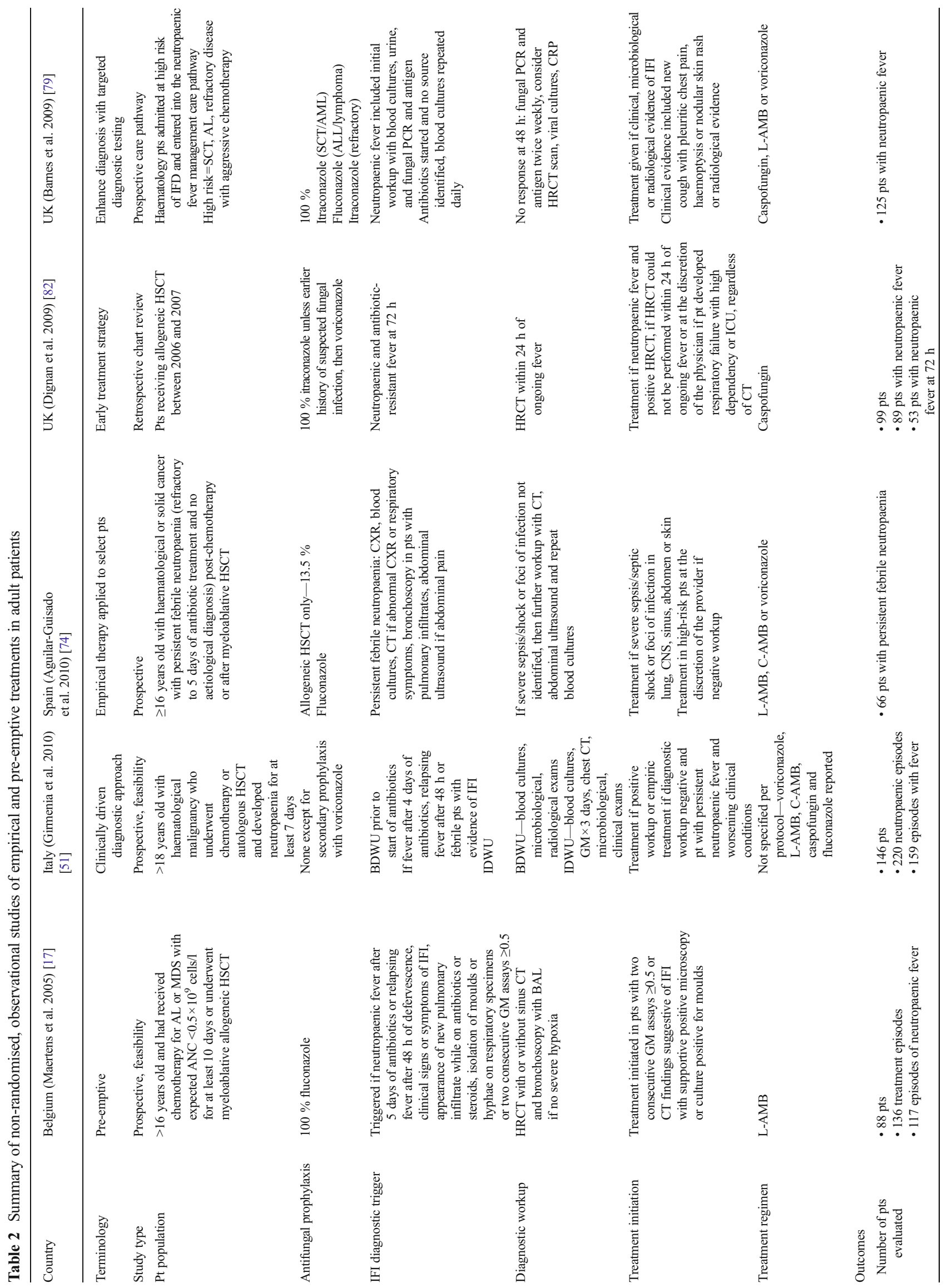




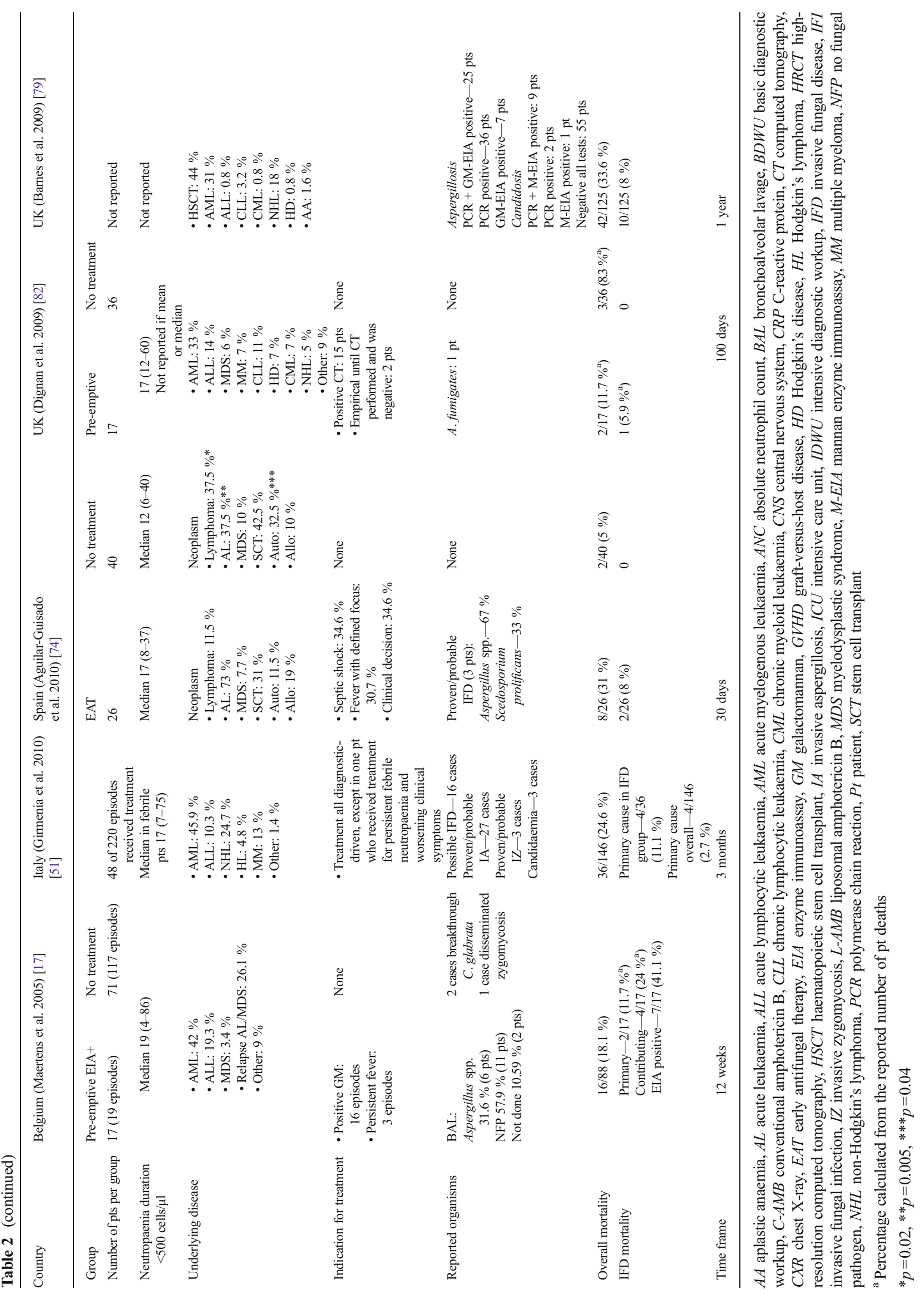




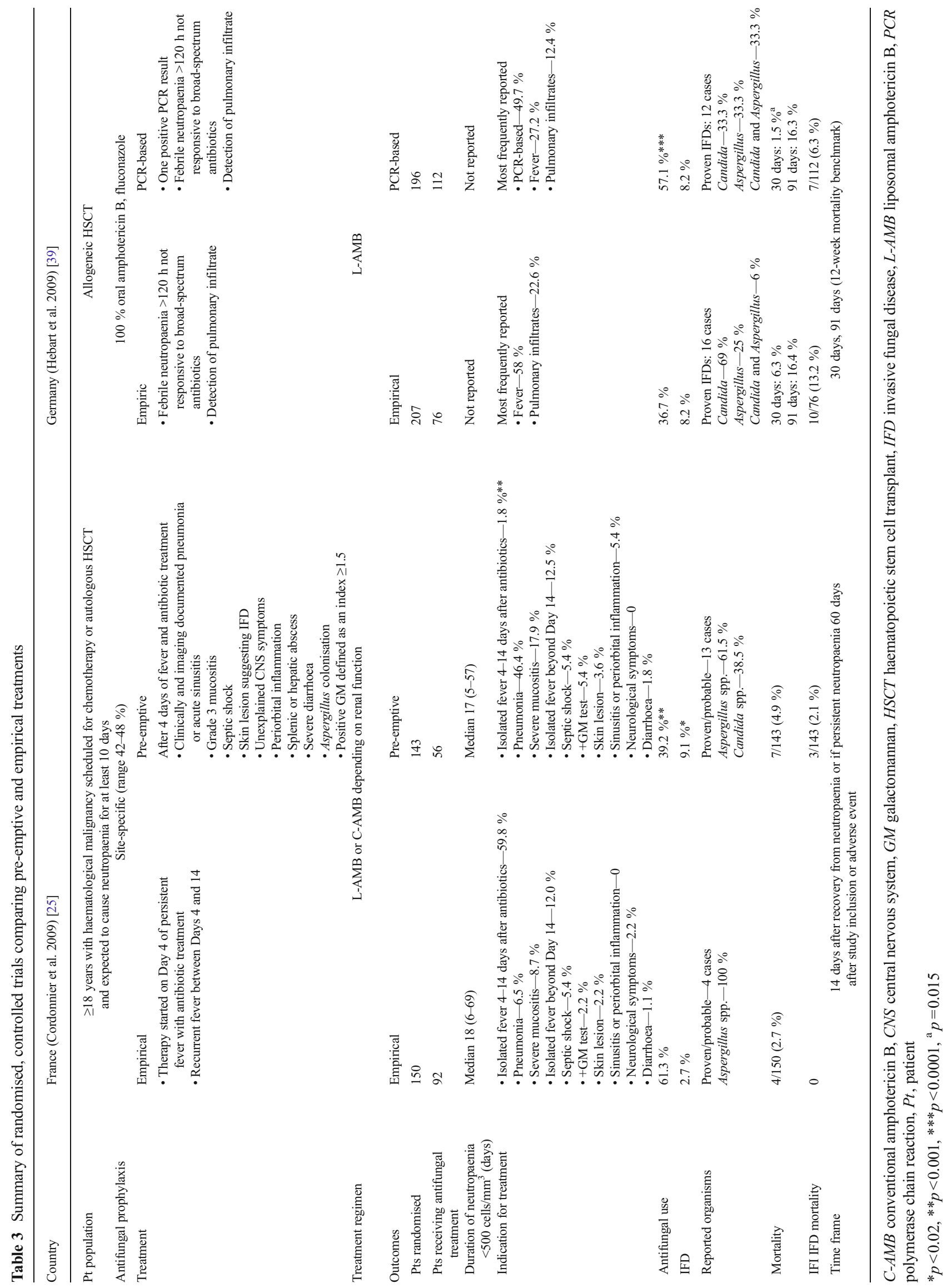


emptively versus empirically. In total, seven IFD cases were missed in three studies. Four proven cases of IFD were missed in the empirical group and one proven case of IFD was missed in the PCR-triggered pre-emptive group reported by Hebart et al. [39]. Maertens and colleagues identified one case of invasive zygomycosis where a patient in the empirical group did not receive antifungal treatment [17]. This patient did not present with fever or other signs of IFDs. By contrast, ten patients were treated pre-emptively due to positive galactomannan testing, despite being non-febrile or having another source of fever identified. These patients had no evidence of IFDs and would not have received treatment via an empirical fever-driven strategy.

Cordonnier and colleagues defined breakthrough infections as infections documented $\geq 24 \mathrm{~h}$ after the first dose of antifungal treatment. The occurrence of breakthrough infections was similar for the empirical and pre-emptive treatment arms (empirical arm Aspergillus infections, $1.3 \%$ of patients; pre-emptive arm Aspergillus species or Candida species, $1.4 \%$ of patients for both organisms) [25]. Two cases of breakthrough candidaemia with $C$. glabrata were identified with blood cultures in a study of pre-emptive treatment by Maertens and colleagues [17].

Overall, excluding the study by Hebart et al. [39], empirical or potentially empirical antifungal use ranged from 35 to $61.3 \%$, while pre-emptive antifungal use ranged from 7.7 to $39.4 \%$. Thus, five out of six studies demonstrated an overall decrease in antifungal use by $43-78 \%$ with the use of a pre-emptive treatment versus empirical strategy [17, 25, 51, 74, 79, 82].

Limited data are available comparing the cost-effectiveness of pre-emptive versus empirical strategies for IFDs. However, a benefit in terms of cost and LOS in high-risk patients has been suggested for pre-emptive treatment [79].

These results emphasise the diverse diagnostic methods and therapeutic modalities that can be used within a preemptive strategy. Various IFDs were represented in the studies, including Candida species. However, when patient populations were consistent, all patients received prophylaxis at baseline and amphotericin B was used by all patients, and outcomes were similar for pre-emptive and empirical treatment strategies [39]. The rates of breakthrough infection were comparable. The rates of antifungal use were lower with preemptive treatment and infection may be detected more frequently using this strategy. Additional studies of pre-emptive antifungal treatment are warranted.

\section{Economic burden of IFDs}

Fifteen studies across eight countries reported economic or HCRU data; these studies reported greater costs in patients with IFDs versus patients without infection. In an observational study in patients with acute myelogenous leukaemia (AML)-myelodysplastic syndromes (MDS) receiving high- dose chemotherapy, the mean total cost per patient was $€ 57,750$ with no IA, €68,280 with possible IA and $€ 83,300$ with probable or proven IA [61]. The additional IA cost burden ranged from $€ 10,530$ to $€ 25,550$, and was statistically significantly greater across all areas of expenditure in patients with possible, probable or proven IA versus patients without IA $(p<0.001)$ [61]. A longer LOS was noted for patients with possible IA (91 days) and probable or proven IA (104 days) versus patients without IA (84 days) [61].

Gangneux and colleagues reported on 50 patients with AML with probable or proven IFD followed for 1 year [29]. LOS for index hospitalisation was 45 days ( $82 \%$ of stays were for malignancy treatment) and the mean duration of antifungal treatment was 198 days [29]. The increase in treatment costs for an IFD episode was $€ 51,033$; antifungals accounted for $€ 35,967$ (70.5\%) of this expenditure during the year [29]. The cost of index hospitalisation was $€ 13,721$, plus $€ 1,345$ for each additional hospitalisation [29]. Berger and colleagues reported on the burden of IFDs in patients who had undergone remission induction chemotherapy for AML or MDS and included those with proven or probable IFD receiving antifungal treatment [35]. Overall, patients with IFDs stayed in hospital 12 days longer than patients without IFDs [35].

The economic impact of IFDs can be assessed from the hospital, payer or societal perspectives. Although the hospital perspective includes only costs that are incurred by the hospital (e.g. costs of diagnostic tests, medications, hospitalisation), the payer perspective includes all direct medical costs (e.g. primary treatment costs, costs of HCRU post-discharge) and the societal perspective includes all direct medical and nonmedical costs (e.g. lost productivity), as well as indirect costs (e.g. future lost productivity).

\section{Hospital perspective}

The hospital perspective costs varied depending on the resources included in the analysis. Costs generally ranged from $€ 8,351$ to $€ 11,821$ when evaluating incremental hospitalisation and antifungal drug expenditure only, $€ 3,930-€ 7,314$ for antifungal drugs, $€ 8,252-€ 51,760$ for hospital bed day costs and $€ 26,596-€ 83,300$ when all direct costs for management were included [35-37, 58, 59, 61, 67, 68, 77, 86].

\section{Payer perspective}

Bruynesteyn and colleagues used a decision tree to compare the cost-effectiveness of caspofungin versus liposomal amphotericin B from the UK National Health Service perspective [80]. The average direct treatment costs were $£ 9,763$ for caspofungin and $£ 11,795$ for liposomal amphotericin $\mathrm{B}$, where the drug costs were $£ 4,601$ and $£ 6,395$, respectively [80]. The difference in other direct costs, including hospitalisation and drug costs related to the management of adverse events, was 
$£ 239$ in favour of caspofungin up to a weight of $77 \mathrm{~kg}$ [80]. Van Campenhout and colleagues compared cost data from an observational study with a model utilising voriconazole for IA therapy [19]. The average total costs of treatment when considering only hospital days associated with fungal infection was $€ 12,376$, and most of this was associated with antifungal use [19].

\section{Societal perspective}

Two studies reported costs from the societal perspective, although one study reported a narrow societal perspective and only included direct costs [40,60]. Both studies used a Markov model and compared voriconazole with conventional amphotericin B for IA, with one study also including itraconazole $[40,60]$. The mean treatment costs for voriconazole and conventional amphotericin $\mathrm{B}$ ranged from $€ 25,353$ to $€ 26,974$ in a 12 -week model and $€ 30,026-€ 33,616$ in a life-long model $[40,60]$.

\section{Summary and discussion}

Despite the availability of a range of therapeutic options, the clinical and economic burden of IFDs remains high.

Considerable variation in reporting methods for IFD-related mortality data was observed, making interpretation difficult. In many cases, denominator data were not included and attributable mortality could not be differentiated from crude mortality. Some studies may have been affected by ascertainment bias $[17,25,63,78]$. The inclusion of some biomarkers (e.g. galactomannan, $\beta$-D-glucan) and not others (e.g. PCR), and the heavy reliance on specific radiological signs in EORTC/ MSG criteria, has led to a stricter definition of IFD, resulting in a significant reduction of possible/probable IFD cases, with an anticipated improvement in specificity for clinical trials [2], However, the criteria are unsuitable for the evaluation of new diagnostic tools because existing criteria are used to define the disease, which may lead to ascertainment bias.

Guidelines provide recommendations for the use of biological tests in adult patients [91, 92]. Although strong evidence supports the use of galactomannan testing in serum, only moderate evidence supports the use of combined mannan/antimannan testing in serum [91]. Anti-mannan antibody testing was not included in this analysis. No PCR recommendations were proposed, owing to a lack of standardisation [91]. HRCT scans and the galactomannan assay were used for diagnosis, although cut-offs and the frequency of testing varied. Utilisation of the (1,3)- $\beta$-d-glucan assay and PCR testing was limited.

A variety of terms were used to describe strategies for the prevention and treatment of IFD, leading to confusion and overlap. Antifungal prophylaxis was used in many studies, but the definition of efficacy or failure varied.
Empirical treatment was generally defined as the initiation of antifungal therapy in a neutropaenic patient with persistent fever, despite broad-spectrum antibiotics for 4 to 7 days. Other terms included universal empirical and early antifungal therapy. Several studies misinterpreted pre-emptive therapy, a strategy which aims to detect infection before clinical disease develops. When clinical and radiological disease is present, the opportunity for the pre-emptive therapy of infection has passed. Other terms identified included clinically driven, diagnostic-driven treatment and targeted prophylaxis/therapy.

Although there is a dearth of studies comparing empirical and pre-emptive treatment strategies, only two randomised, controlled studies were identified. The variations in diagnosis and treatment in these studies led to difficulties in developing conclusions regarding the role of pre-emptive therapy. A prospective, randomised clinical study comparing empirical and diagnostic-driven (pre-emptive) therapy in patients with acute leukaemia or undergoing allogeneic SCT is ongoing in European centres (NCT01288378).

Studies assessing the economic burden of IFDs are limited; the incremental cost burden is estimated to be between $€ 10,530$ and $€ 51,033$, depending on the certainty of infection and the duration of follow-up. Drivers of HCRU burden included hospitalisation, diagnostic testing and medications. To demonstrate a clear cost benefit, further evidence that a pre-emptive strategy decreases antifungal use compared with a standard empirical approach is needed.

In conclusion, the primary evidence reported here demonstrates the importance of IFDs in Europe and highlights the need for early and appropriate therapy, facilitated by new techniques for more rapid diagnosis. Additional studies are required in order to establish the clinical and economic burden of IFDs, and assess current treatment practices.

Acknowledgments The authors would like to thank Robyn Mays, PharmD from Pharmerit International for her assistance in conducting the research. The literature review was sponsored by Pfizer Inc. Editorial support was provided by Karen Irving of Complete Medical Communications, and was funded by Pfizer Inc.

Conflict of interest L. Drgona has served as a consultant for Astellas, Pfizer Inc. and MSD, and is a member of the advisory board for Pfizer Inc.

J. Stephens and A. Khachatryan are employees of Pharmerit International, and have served as consultants for Pfizer Inc.

C. Charbonneau, M. Kantecki and S. Haider are employees of Pfizer Inc. and hold stock/stock options in Pfizer Inc.

R. Barnes has served on advisory boards, and has received sponsorship and travel expenses to attend meetings and honoraria for lectures/ symposia from Astellas, Gilead Sciences, MSD and Pfizer Inc. She has also received an educational grant, scientific fellowship awards and independent researcher grants from Gilead Sciences and Pfizer Inc. She is a member of the European Aspergillus PCR Initiative Working Group of the International Society for Human and Animal Mycology and a board member of the European Aspergillus PCR Initiative Foundation, which is registered according to Dutch Law with the Chamber of Commerce, number 09165918. 
Open Access This article is distributed under the terms of the Creative Commons Attribution License which permits any use, distribution, and reproduction in any medium, provided the original author(s) and the source are credited.

\section{References}

1. Menzin J, Meyers JL, Friedman M, Perfect JR, Langston AA, Danna RP, Papadopoulos G (2009) Mortality, length of hospitalization, and costs associated with invasive fungal infections in high-risk patients. Am J Health Syst Pharm 66:1711-1717

2. De Pauw B, Walsh TJ, Donnelly JP, Stevens DA, Edwards JE, Calandra T, Pappas PG, Maertens J, Lortholary O, Kauffman CA, Denning DW, Patterson TF, Maschmeyer G, Bille J, Dismukes WE, Herbrecht R, Hope WW, Kibbler CC, Kullberg BJ, Marr KA, Muñoz P, Odds FC, Perfect JR, Restrepo A, Ruhnke M, Segal BH, Sobel JD, Sorrell TC, Viscoli C, Wingard JR, Zaoutis T, Bennett JE; European Organization for Research and Treatment of Cancer/Invasive Fungal Infections Cooperative Group; National Institute of Allergy and Infectious Diseases Mycoses Study Group (EORTC/MSG) Consensus Group (2008) Revised definitions of invasive fungal disease from the European Organization for Research and Treatment of Cancer/Invasive Fungal Infections Cooperative Group and the National Institute of Allergy and Infectious Diseases Mycoses Study Group (EORTC/ MSG) Consensus Group. Clin Infect Dis 46:1813-1821

3. Robenshtok E, Gafter-Gvili A, Goldberg E, Weinberger M, Yeshurun M, Leibovici L, Paul M (2007) Antifungal prophylaxis in cancer patients after chemotherapy or hematopoietic stem-cell transplantation: systematic review and meta-analysis. J Clin Oncol 25:5471-5489

4. Segal BH, Freifeld AG, Baden LR, Brown AE, Casper C, Dubberke E, Gelfand M, Greene JN, Ison MG, Ito JI, Karp JE, Kaul DR, King E, Mackler E, Marcucci G, Montoya JG, Engemann AM, Rolston K, The AS (2008) Prevention and treatment of cancer-related infections. J Natl Compr Canc Netw 6:122-174

5. Cornely OA, Böhme A, Buchheidt D, Einsele H, Heinz WJ, Karthaus M, Krause SW, Krüger W, Maschmeyer G, Penack O, Ritter J, Ruhnke M, Sandherr M, Sieniawski M, Vehreschild JJ, Wolf HH, Ullmann AJ (2009) Primary prophylaxis of invasive fungal infections in patients with hematologic malignancies. Recommendations of the Infectious Diseases Working Party of the German Society for Haematology and Oncology. Haematologica 94:113-122

6. Walsh TJ, Anaissie EJ, Denning DW, Herbrecht R, Kontoyiannis DP, Marr KA, Morrison VA, Segal BH, Steinbach WJ, Stevens DA, van Burik JA, Wingard JR, Patterson TF; Infectious Diseases Society of America (2008) Treatment of aspergillosis: clinical practice guidelines of the Infectious Diseases Society of America. Clin Infect Dis 46:327-360

7. Freemantle N, Tharmanathan P, Herbrecht R (2011) Systematic review and mixed treatment comparison of randomized evidence for empirical, pre-emptive and directed treatment strategies for invasive mould disease. J Antimicrob Chemother 66(Suppl 1):i25-i35

8. Herbrecht R, Berceanu A (2008) Beta-D-glucan detection test: a step toward preemptive therapy for fungal infections in leukemic patients? Clin Infect Dis 46:886-889

9. Steinbach WJ, Juvvadi PR, Fortwendel JR, Rogg LE (2011) Newer combination antifungal therapies for invasive aspergillosis. Med Mycol 49(Suppl 1):S77-S81

10. Pappas PG, Kauffman CA, Andes D, Benjamin DK Jr, Calandra TF, Edwards JE Jr, Filler SG, Fisher JF, Kullberg BJ, Ostrosky-Zeichner L, Reboli AC, Rex JH, Walsh TJ, Sobel JD; Infectious Diseases Society of America (2009) Clinical practice guidelines for the management of candidiasis: 2009 update by the Infectious Diseases Society of America. Clin Infect Dis 48:503-535
11. Mosquera J, Denning DW (2002) Azole cross-resistance in Aspergillus fumigatus. Antimicrob Agents Chemother 46:556-557

12. Wilson DT, Drew RH, Perfect JR (2009) Antifungal therapy for invasive fungal diseases in allogeneic stem cell transplant recipients: an update. Mycopathologia 168:313-327

13. Herbrecht R, Denning DW, Patterson TF, Bennett JE, Greene RE, Oestmann JW, Kern WV, Marr KA, Ribaud P, Lortholary O, Sylvester R, Rubin RH, Wingard JR, Stark P, Durand C, Caillot D, Thiel E, Chandrasekar PH, Hodges MR, Schlamm HT, Troke PF, de Pauw B; Invasive Fungal Infections Group of the European Organisation for Research and Treatment of Cancer and the Global Aspergillus Study Group (2002) Voriconazole versus amphotericin B for primary therapy of invasive aspergillosis. N Engl J Med 347:408-415

14. Lass-Flörl C, Griff K, Mayr A, Petzer A, Gastl G, Bonatti H, Freund M, Kropshofer G, Dierich MP, Nachbaur D (2005) Epidemiology and outcome of infections due to Aspergillus terreus: 10-year single centre experience. Br J Haematol 131:201-207

15. Perkhofer S, Lass-Flörl C, Hell M, Russ G, Krause R, Hönigl M, Geltner C, Auberger J, Gastl G, Mitterbauer M, Willinger B, Knöbl P, Resch G, Waldner R, Makrai A, Hartmann G, Girschikofsky M, Greil R (2010) The Nationwide Austrian Aspergillus Registry: a prospective data collection on epidemiology, therapy and outcome of invasive mould infections in immunocompromised and/or immunosuppressed patients. Int J Antimicrob Agents 36:531-536

16. Presterl E, Daxböck F, Graninger W, Willinger B (2007) Changing pattern of candidaemia 2001-2006 and use of antifungal therapy at the University Hospital of Vienna, Austria. Clin Microbiol Infect 13:1072-1076

17. Maertens J, Theunissen K, Verhoef G, Verschakelen J, Lagrou K, Verbeken E, Wilmer A, Verhaegen J, Boogaerts M, Van Eldere J (2005) Galactomannan and computed tomography-based preemptive antifungal therapy in neutropenic patients at high risk for invasive fungal infection: a prospective feasibility study. Clin Infect Dis 41:1242-1250

18. Meersseman W, Vandecasteele SJ, Wilmer A, Verbeken E, Peetermans WE, Van Wijngaerden E (2004) Invasive aspergillosis in critically ill patients without malignancy. Am J Respir Crit Care Med 170:621-625

19. Van Campenhout H, Marbaix S, Derde MP, Annemans L (2008) Voriconazole treatment of invasive aspergillosis: real-world versus health-economic model results. Clin Drug Investig 28:509-521

20. Vandewoude K, Blot S, Benoit D, Depuydt P, Vogelaers D, Colardyn F (2004) Invasive aspergillosis in critically ill patients: analysis of risk factors for acquisition and mortality. Acta Clin Belg 59:251-257

21. Anttila VJ, Salonen J, Ylipalosaari P, Koivula I, Riikonen P, Nikoskelainen J (2007) A retrospective nationwide case study on the use of a new antifungal agent: patients treated with caspofungin during 2001-2004 in Finland. Clin Microbiol Infect 13:606-612

22. Jantunen E, Salonen J, Juvonen E, Koivunen E, Siitonen T, Lehtinen T, Kuittinen O, Leppä S, Anttila VJ, Itälä M, Wiklund T, Remes K, Nousiainen T (2004) Invasive fungal infections in autologous stem cell transplant recipients: a nation-wide study of 1188 transplanted patients. Eur J Haematol 73:174-178

23. Bénet T, Nicolle MC, Thiebaut A, Piens MA, Nicolini FE, Thomas X, Picot S, Michallet M, Vanhems P (2007) Reduction of invasive aspergillosis incidence among immunocompromised patients after control of environmental exposure. Clin Infect Dis 45:682-686

24. Cordonnier C, Ribaud P, Herbrecht R, Milpied N, Valteau-Couanet D, Morgan C, Wade A; Société Française de Greffe de Moelle et de Thérapie Cellulaire (2006) Prognostic factors for death due to invasive aspergillosis after hematopoietic stem cell transplantation: a 1year retrospective study of consecutive patients at French transplantation centers. Clin Infect Dis 42:955-963

25. Cordonnier C, Pautas C, Maury S, Vekhoff A, Farhat H, Suarez F, Dhédin N, Isnard F, Ades L, Kuhnowski F, Foulet F, Kuentz M, Maison P, Bretagne S, Schwarzinger M (2009) Empirical versus 
preemptive antifungal therapy for high-risk, febrile, neutropenic patients: a randomized, controlled trial. Clin Infect Dis 48:1042-1051

26. Cornet M, Fleury L, Maslo C, Bernard JF, Brücker G; Invasive Aspergillosis Surveillance Network of the Assistance PubliqueHôpitaux de Paris (2002) Epidemiology of invasive aspergillosis in France: a six-year multicentric survey in the Greater Paris area. J Hosp Infect 51:288-296

27. Fourneret-Vivier A, Lebeau B, Mallaret MR, Brenier-Pinchart MP, Brion JP, Pinel C, Garban F, Pison C, Hamidfar R, Plantaz D, Pelloux H, Grillot R (2006) Hospital-wide prospective mandatory surveillance of invasive aspergillosis in a French teaching hospital (2000 2002). J Hosp Infect 62:22-28

28. Gallien S, Fournier S, Porcher R, Bottero J, Ribaud P, Sulahian A, Socié G, Molina JM (2008) Therapeutic outcome and prognostic factors of invasive aspergillosis in an infectious disease department: a review of 34 cases. Infection 36:533-538

29. Gangneux J, DuPont B, Michalet M, Herbrecht R, Ribaud P, Caillot D, Moreau P, Berger P, Lafuma A (2008) Associated medical consumption and costs during invasive fungal infection in acute myeloblastic leukemia patients in France. Abstract presented at the Interscience Conference on Antimicrobial Agents and Chemotherapy/ Infectious Diseases Society of America, Washington, DC, USA, October 25-28 2008

30. Herbrecht R, Cordonnier C, Gangneux J, Caillot D, Auvrignon A, Thiebaut A, Gorin N, Brethon B, Michallet M., Fisher A, Bertrand Y, Preziosi P, Ruiz F (2010) Management and outcomes of invasive fungal diseases (IFD) in patients with hematological malignancies: a French Cohort study. Abstract presented at the Interscience Conference on Antimicrobial Agents and Chemotherapy, Boston, MA, USA, September 12-15 2010

31. Lafaurie M, Lapalu J, Raffoux E, Breton B, Lacroix C, Socié G, Porcher R, Ribaud P, Touratier S, Molina JM (2010) High rate of breakthrough invasive aspergillosis among patients receiving caspofungin for persistent fever and neutropenia. Clin Microbiol Infect 16:1191-1196

32. Leroy O, Gangneux JP, Montravers P, Mira JP, Gouin F, Sollet JP, Carlet J, Reynes J, Rosenheim M, Regnier B, Lortholary O; AmarCand Study Group (2009) Epidemiology, management, and risk factors for death of invasive Candida infections in critical care: a multicenter, prospective, observational study in France (20052006). Crit Care Med 37:1612-1618

33. Lortholary O, Charlemagne A, Bastides F, Chevalier P, Datry A, Gonzalves MF, Michel G, Tilleul P, Veber B, Herbrecht R (2004) A multicentre pharmacoepidemiological study of therapeutic practices in invasive fungal infections in France during 1998-1999. J Antimicrob Chemother 54:456-464

34. Michallet M, Benet T, Kraghel S, Sobh M, El Hamri M, Cannas G, Nicolini F, Labussiere H, Duscastelle-Lepretre S, Barraco F, Chelghoum Y, Thomas X, Nicoll M, Bienvenu A, Persat F, Vanhems $P$ (2010) Invasive aspergillosis: a new important risk factor on short and long-term survival of AML patients. Haematologica 95:30

35. Berger K, Cornely O, Hoppe-Tichy T, Kiehl M, Knoth H, Rieger C, Thalheimer M, Schuler U, Ullmann A, Osterman H (2008) Invasive fungal infection (IFI) in patients with acute myelogenous (AML) or myslodysplastic syndrome (MDS) - treatment cost from hospital perspective. Abstract presented at the International Society for Pharmacoeconomics and Outcome Research 11th Annual European Congress, Athens, Greece, November 8-11 2008

36. Boehme A, Atta J, Mousset S, Steffan B, Serve H, Hoelzer D, Shlaen R, Ehlken B, Bug G (2010) Change of antifungal treatment patterns and associated costs in patients with acute myelogenous leukemia (AML) after chemotherapy in a German hospital from 2004 to 2006. Abstract presented at the International Society for Pharmacoeconomics and Outcome Research 13th Annual European Congress, Prague, Czech Republic, November 6-9 2010
37. Cornely OA, Sidhu M, Odeyemi I, van Engen AK, van der Waal JM, Schoeman O (2008) Economic analysis of micafungin versus liposomal amphotericin B for treatment of candidaemia and invasive candidiasis in Germany. Curr Med Res Opin 24:1743-1753

38. Hahn-Ast C, Glasmacher A, Mückter S, Schmitz A, Kraemer A, Marklein G, Brossart P, von Lilienfeld-Toal M (2010) Overall survival and fungal infection-related mortality in patients with invasive fungal infection and neutropenia after myelosuppressive chemotherapy in a tertiary care centre from 1995 to 2006 . J Antimicrob Chemother 65:761-768

39. Hebart H, Klingspor L, Klingebiel T, Loeffler J, Tollemar J, Ljungman P, Wandt H, Schaefer-Eckart K, Dornbusch HJ, Meisner C, Engel C, Stenger N, Mayer T, Ringden O, Einsele H (2009) A prospective randomized controlled trial comparing PCR-based and empirical treatment with liposomal amphotericin B in patients after allo-SCT. Bone Marrow Transplant 43:553-561

40. Jansen JP, Kern WV, Cornely OA, Karthaus M, Ruhnke M, Ullmann AJ, Resch A (2006) Economic evaluation of voriconazole versus conventional amphotericin B in the treatment of invasive aspergillosis in Germany. Value Health 9:12-23

41. Kovalevskaya E, Hummel M, Spiess B, Buchheidt D (2008) Investigating non-blood specimens of neutropenic patients with hematological malignancies with a nested Aspergillus PCR assay: clinical results. Abstract presented at the Interscience Conference on Antimicrobial Agents and Chemotherapy/Infectious Diseases Society of America, Washington, DC, USA, October 25-28 2008

42. Lehrnbecher T, Frank C, Engels K, Kriener S, Groll AH, Schwabe D (2010) Trends in the postmortem epidemiology of invasive fungal infections at a university hospital. J Infect 61:259-265

43. Schwesinger G, Junghans D, Schröder G, Bernhardt H, Knoke M (2005) Candidosis and aspergillosis as autopsy findings from 1994 to 2003. Mycoses 48:176-180

44. Spiliopoulou A, Vamvacopoulou S, Bartzavali C, Picoula L, Anastassiou L, Christofidon M (2009) Candidemia: retrospective analysis of eleven year experience. Poster presented at the Interscience Conference on Antimicrobial Agents and Chemotherapy Annual Conference, San Francisco, CA, USA, September 12-14 2012

45. Dimopoulos G, Ntziora F, Rachiotis G, Armaganidis A, Falagas ME (2008) Candida albicans versus non-albicans intensive care unitacquired bloodstream infections: differences in risk factors and outcome. Anesth Analg 106:523-529

46. Roilides E, Farmaki E, Evdoridou J, Dotis J, Hatziioannidis E, Tsivitanidou M, Bibashi E, Filioti I, Sofianou D, Gil-Lamaignere C, Mueller FM, Kremenopoulos G (2004) Neonatal candidiasis: analysis of epidemiology, drug susceptibility, and molecular typing of causative isolates. Eur J Clin Microbiol Infect Dis 23:745-750

47. Boo TW, O'Reilly B, O'Leary J, Cryan B (2005) Candidaemia in an Irish tertiary referral hospital: epidemiology and prognostic factors. Mycoses 48:251-259

48. Scanlon N, Jaura A, Fraher M, Collins C, Marsh B, McWade R, Hannan M (2008) A change in epidemiology of fungal infections in ICU patients: the impact of antifungal therapy. Abstract presented at the Interscience Conference on Antimicrobial Agents and Chemotherapy/Infectious Diseases Society of America, Washington, DC, USA, October 25-28 2008

49. Bedini A, Venturelli C, Mussini C, Guaraldi G, Codeluppi M, Borghi V, Rumpianesi F, Barchiesi F, Esposito R (2006) Epidemiology of candidaemia and antifungal susceptibility patterns in an Italian tertiary-care hospital. Clin Microbiol Infect 12:75-80

50. Girmenia C, Pizzarelli G, Cristini F, Barchiesi F, Spreghini E, Scalise G, Martino P (2006) Candida guilliermondii fungemia in patients with hematologic malignancies. J Clin Microbiol 44:2458-2464

51. Girmenia C, Micozzi A, Gentile G, Santilli S, Arleo E, Cardarelli L, Capria S, Minotti C, Cartoni C, Brocchieri S, Guerrisi V, Meloni G, Foà R, Martino P (2010) Clinically driven diagnostic antifungal 
approach in neutropenic patients: a prospective feasibility study. $\mathrm{J}$ Clin Oncol 28:667-674

52. Lequaglie C (2002) Liposomal amphotericin B (AmBisome): efficacy and safety of low-dose therapy in pulmonary fungal infections. J Antimicrob Chemother 49(Suppl 1):49-50

53. Libanore M, Prini E, Mazzetti M, Barchi E, Raise E, Gritti FM, Bonazzi L, Ghinelli F (2002) Invasive aspergillosis in Italian AIDS patients. Infection 30:341-345

54. Pagano L, Caira M, Nosari A, Van Lint MT, Candoni A, Offidani M, Aloisi T, Irrera G, Bonini A, Picardi M, Caramatti C, Invernizzi R, Mattei D, Melillo L, de Waure C, Reddiconto G, Fianchi L, Valentini CG, Girmenia C, Leone G, Aversa F (2007) Fungal infections in recipients of hematopoietic stem cell transplants: results of the SEIFEM B-2004 study-Sorveglianza Epidemiologica Infezioni Fungine Nelle Emopatie Maligne. Clin Infect Dis 45:1161-1170

55. Pagano L, Caira M, Candoni A, Offidani M, Martino B, Specchia G, Pastore D, Stanzani M, Cattaneo C, Fanci R, Caramatti C, Rossini F, Luppi M, Potenza L, Ferrara F, Mitra ME, Fadda RM, Invernizzi R, Aloisi T, Picardi M, Bonini A, Vacca A, Chierichini A, Melillo L, de Waure C, Fianchi L, Riva M, Leone G, Aversa F, Nosari A (2010) Invasive aspergillosis in patients with acute myeloid leukemia: a SEIFEM-2008 registry study. Haematologica 95:644-650

56. Posteraro B, Sanguinetti M, Boccia S, De Feo E, La Sorda M, Tana M, Tirone C, Aurilia C, Vendettuoli V, Fadda G, Romagnoli C, Vento G (2010) Early mannan detection in bronchoalveolar lavage fluid with preemptive treatment reduces the incidence of invasive Candida infections in preterm infants. Pediatr Infect Dis J 29:844-848

57. Riva M, Nosari A, Rizio A, Molteni A, Vanelli C, Gabutti C, Nador G, Morra E (2008) In high risk acute leukemia patients early antifungal therapy (EAT) improves the outcome of invasive mould infections. Abstract presented at the Interscience Conference on Antimicrobial Agents and Chemotherapy/Infectious Diseases Society of America, Washington, DC, USA, October 25-28 2008

58. Stam WB, O'Sullivan AK, Rijnders B, Lugtenburg E, Span LF, Janssen JJ, Jansen JP (2008) Economic evaluation of posaconazole vs. standard azole prophylaxis in high risk neutropenic patients in the Netherlands. Eur J Haematol 81:467-474

59. Ament AJ, Hübben MW, Verweij PE, de Groot R, Warris A, Donnelly JP, van't Wout J, Severens JL (2007) Economic evaluation of targeted treatments of invasive aspergillosis in adult haematopoietic stem cell transplant recipients in the Netherlands: a modelling approach. J Antimicrob Chemother 60:385-393

60. Jansen JP, Meis JF, Blijlevens NM, van't Wout JW (2005) Economic evaluation of voriconazole in the treatment of invasive aspergillosis in the Netherlands. Curr Med Res Opin 21:1535-1546

61. Slobbe L, Polinder S, Doorduijn JK, Lugtenburg PJ, el Barzouhi A, Steyerberg EW, Rijnders BJ (2008) Outcome and medical costs of patients with invasive aspergillosis and acute myelogenous leukemia-myelodysplastic syndrome treated with intensive chemotherapy: an observational study. Clin Infect Dis 47:1507-1512

62. Odds FC, Hanson MF, Davidson AD, Jacobsen MD, Wright P, Whyte JA, Gow NA, Jones BL (2007) One year prospective survey of Candida bloodstream infections in Scotland. J Med Microbiol 56:1066-1075

63. Allam MF, Del Castillo AS, Díaz-Molina C, Navajas RF (2002) Invasive pulmonary aspergillosis: identification of risk factors. Scand J Infect Dis 34:819-822

64. Almirante B, Rodríguez D, Cuenca-Estrella M, Almela M, Sanchez F, Ayats J, Alonso-Tarres C, Rodriguez-Tudela JL, Pahissa A (2006) Epidemiology, risk factors, and prognosis of Candida parapsilosis bloodstream infections: case-control population-based surveillance study of patients in Barcelona, Spain, from 2002 to 2003. J Clin Microbiol 44:1681-1685

65. Bouza E, Guinea J, Peláez T, Pérez-Molina J, Alcalá L, Muñoz P (2005) Workload due to Aspergillus fumigatus and significance of the organism in the microbiology laboratory of a general hospital. J Clin Microbiol 43:2075-2079

66. Cisterna R, Ezpeleta G, Telleria O (2010) A multicenter antifungal susceptibility study of invasive Candida spp. infection in Spain. Abstract presented at the Interscience Conference on Antimicrobial Agents and Chemotherapy, Boston, MA, USA, September 12-15 2010

67. Martin-Pena A, Gil-Navarro M, Aguilar-Guisado M, Espigado I, Cordero E, Pachon J, Cisneros J (2010) Cost-effectiveness study of empirical antifungal strategies in patients with persistent febrile neutropenia. Abstract presented at the Interscience Conference on Antimicrobial Agents and Chemotherapy, Boston, MA, USA, September 12-15 2010

68. Domínguez-Gil A, Martín I, García Vargas M, Del Castillo A, Díaz S, Sánchez C (2007) Economic evaluation of voriconazole versus caspofungin for the treatment of invasive aspergillosis in Spain. Clin Drug Investig 27:197-205

69. Fortun J, Martin-Davila P, Ros L, Luengo J, Agundez M, SanchezSousa A et al (2009) Impact of epidemiological changes in candidemia on outcome. Abstract presented at the Interscience Conference on Antimicrobial Agents and Chemotherapy, San Francisco, CA, USA, September 12-14 2009

70. Garcia M, Marti B, Ferro B (2009) Budget impact analysis of three candins in the treatment of invasive candidiasis in adult nonneutropenic patients in Spain. Abstract presented at the International Society for Pharmacoeconomics and Outcome Research 12th Annual European Congress, Paris, France, October 24-27 2009

71. Garnacho-Montero J, Díaz-Martín A, García-Cabrera E, Ruiz Pérez de Pipaón M, Hernández-Caballero C, Aznar-Martín J, Cisneros JM, Ortiz-Leyba C (2010) Risk factors for fluconazole-resistant candidemia. Antimicrob Agents Chemother 54:3149-3154

72. Guinea J, Jenson J, Torres-Narbona M, Gijon Pelaez T, Munoz P, Bouza E (2008) Chronic obstructive pulmonary disease (COPD) is currently the most predisposing condition to invasive aspergillosis. Abstract presented at the Interscience Conference on Antimicrobial Agents and Chemotherapy/Infectious Diseases Society of America, Washington, DC, USA, October 25-28 2008

73. Guinea J, Torres-Narbona M, Gijon Pelaez T, Munoz P, Bouza E (2008) Invasive pulmonary aspergillosis (IPA) in patients with COPD: a description of 57 cases collected in a single tertiary hospital (1999-2008). Abstract presented at the Interscience Conference on Antimicrobial Agents and Chemotherapy/Infectious Diseases Society of America, Washington, DC, USA, October 25-28 2008

74. Aguilar-Guisado M, Espigado I, Cordero E, Noguer M, Parody R, Pachón J, Cisneros JM (2010) Empirical antifungal therapy in selected patients with persistent febrile neutropenia. Bone Marrow Transplant 45:159-164

75. Ortega M, Alemla M, Soriano A, Marco F, Martinez J, Pitart C, Nicolau C, Mensa J (2010) Analysis of 540 episodes of Candida bloodstream infection isolated in a single institution from Barcelona: impact of treatment in outcome. Abstract presented at the Interscience Conference on Antimicrobial Agents and Chemotherapy, Boston, MA, USA, September 12-15 2010

76. Rubio PM, Sevilla J, González-Vicent M, Lassaletta A, CuencaEstrella M, Díaz MA, Riesco S, Madero L (2009) Increasing incidence of invasive aspergillosis in pediatric hematology oncology patients over the last decade: a retrospective single centre study. J Pediatr Hematol Oncol 31:642-646

77. Garbino J, Schnetzler G, Roberts C (2005) Invasive aspergillosis: is treatment with "inexpensive" amphotericin B cost saving if "expensive" voriconazole is only used on demand? Swiss Med Wkly 135:624-630

78. Weisser M, Rausch C, Droll A, Simcock M, Sendi P, Steffen I, Buitrago C, Sonnet S, Gratwohl A, Passweg J, Fluckiger U (2005) Galactomannan does not precede major signs on a pulmonary computerized tomographic scan suggestive of invasive aspergillosis in patients with hematological malignancies. Clin Infect Dis 41:1143-1149 
79. Barnes RA, White PL, Bygrave C, Evans N, Healy B, Kell J (2009) Clinical impact of enhanced diagnosis of invasive fungal disease in high-risk haematology and stem cell transplant patients. J Clin Pathol 62:64-69

80. Bruynesteyn K, Gant V, McKenzie C, Pagliuca T, Poynton C, Kumar RN, Jansen JP (2007) A cost-effectiveness analysis of caspofungin vs. liposomal amphotericin B for treatment of suspected fungal infections in the UK. Eur J Haematol 78:532-539

81. Clerihew L, Lamagni TL, Brocklehurst P, McGuire W (2007) Candida parapsilosis infection in very low birthweight infants. Arch Dis Child Fetal Neonatal Ed 92:F127-F129

82. Dignan FL, Evans SO, Ethell ME, Shaw BE, Davies FE, Dearden CE, Treleaven JG, Riley UB, Morgan GJ, Potter MN (2009) An early CTdiagnosis-based treatment strategy for invasive fungal infection in allogeneic transplant recipients using caspofungin first line: an effective strategy with low mortality. Bone Marrow Transplant 44:51-56

83. Edi-Osagie NE, Emmerson AJ (2005) Seasonality of invasive Candida infection in neonates. Acta Paediatr 94:72-74

84. El-Masry FA, Neal TJ, Subhedar NV (2002) Risk factors for invasive fungal infection in neonates. Acta Paediatr 91:198-202

85. Schelenz S, Barnes RA, Kibbler CC, Jones BL, Denning DW (2009) Standards of care for patients with invasive fungal infections within the United Kingdom: a national audit. J Infect 58:145-153

86. Sidhu MK, van Engen AK, Kleintjens J, Schoeman O, Palazzo M (2009) Cost-effectiveness analysis of micafungin versus caspofungin for treatment of systemic Candida infections in the UK. Curr Med Res Opin 25:2049-2059

87. Lortholary O, Ascioglu S, Moreau P, Herbrecht R, Marinus A, Casassus P, De Pauw B, Denning DW (2000) Invasive aspergillosis as an opportunistic infection in nonallografted patients with multiple myeloma: a European Organization for Research and Treatment of
Cancer/Invasive Fungal Infections Cooperative Group and the Intergroupe Français du Myélome. Clin Infect Dis 30:41-46

88. Tortorano AM, Peman J, Bernhardt H, Klingspor L, Kibbler CC, Faure O, Biraghi E, Canton E, Zimmermann K, Seaton S, Grillot R; ECMM Working Group on Candidaemia (2004) Epidemiology of candidaemia in Europe: results of 28-month European Confederation of Medical Mycology (ECMM) hospital-based surveillance study. Eur J Clin Microbiol Infect Dis 23:317-322

89. Drgona L, Trupl J, Hupkova H (2010) Clinical analysis of 92 patients with fungaemia - data from national survey in Slovak. Poster presented at the 14th International Congress on Infectious Diseases, Miami, FL, USA, March 9-12 2010

90. Drgona L, Kotulova D, Trupl J, Kunova A, Hupkova H, Lisalova M, Marcek T (2011) Trends of candidaemia in Slovakia - a comparison of two consecutive, prospective studies. Poster presented at the 21st European Congress of Clinical Microbiology and Infectious Diseases, Milan, Italy, May 7-10 2011

91. Marchetti O, Lamoth F, Mikulska M, Viscoli C, Verweij P, Bretagne $\mathrm{S}$; European Conference on Infections in Leukemia (ECIL) Laboratory Working Groups (2012) ECIL recommendations for the use of biological markers for the diagnosis of invasive fungal diseases in leukemic patients and hematopoietic SCT recipients. Bone Marrow Transplant 47:846-854

92. Cuenca-Estrella M, Verweij PE, Arendrup MC, Arikan-Akdagli S, Bille J, Donnelly JP, Jensen HE, Lass-Flörl C, Richardson MD, Akova M, Bassetti M, Calandra T, Castagnola E, Cornely OA, Garbino J, Groll AH, Herbrecht R, Hope WW, Kullberg BJ, Lortholary O, Meersseman W, Petrikkos G, Roilides E, Viscoli C, Ullmann AJ; ESCMID Fungal Infection Study Group (2012) ESCMID* guideline for the diagnosis and management of Candida diseases 2012: diagnostic procedures. Clin Microbiol Infect 18(Suppl 7):9-18 